\title{
Seasonal Variation of Ozone at Washington, D. C.
}

\author{
By Ralph Stair
}

\begin{abstract}
This paper gives data on the variation in the total amount of ozone in the atmosphere above Washington, D. C., covering a 9-year period extending from 1934 to 1943 . The amount of ozone was determined from solar ultraviolet measurements made by means of a phototube and filter method on direct sunlight.

The ozone determinations indicate a seasonal variation having a maximum value during late winter and early spring (range 0.20 to 0.30 centimeters normal-temperature pressure) with a minimum value in late summer or early fall (range 0.16 to 0.20 centimeters normaltemperature pressure).

No correlation appears to exist between total ozone value and surface pressure pattern or between ozone value and sunspot number. A close correlation does, however, exist between total ozone and air temperatures at altitudes near 8 kilometers, that is, within the upper part of the troposphere. A slight opposite correlation appears to hold for altitudes within the stratosphere, with the change-over occurring near the level of the tropopause.
\end{abstract}

\section{Introduction}

The data on the variation in the total amount of ozone above Washington, D. C., recorded in this paper are based upon measurements of direct ultraviolet solar radiant energy made on clear days at the National Bureau of Standards. The original data were obtained in collaboration with W. W. Coblentz, formerly Chief of the radiometry laboratory of this Bureau, and represent 244 days within a 9-year period extending from 1934 to 1943. Ordinarily measurements were made only on days when there was little smoke or haze and the sky was relatively free from clouds. During most of the days on which measurements were made, the wind was from a westerly direction which, coupled with the fact that the observing station is in the northwest edge of the city, resulted in essentially "country air" conditions. Except during the winter months when the solar altitudes were low, even at noon, most of the measurements employed in this work were obtained through an air mass not exceeding 1.5 atmospheres, so that most of the data are based on measurements of high-intensity ultraviolet solar radiant flux densities.

The method employed in this work involves the use of titanium phototubes sensitive to solar radiant energy between about 3,000 and 3,400 A, together with glass filters having transmittances beginning at 2,900 to $3,100 \mathrm{~A}$ and increasing with wavelength. Since ozone is strongly absorbing within this region of the spectrum, any change in its value is immediately reflected as a change in the observed transmittance of the filters. Likewise, a change in the relative spectral emission of the sun would produce a similar change in the observed filter transmittance. Although it is known that there are large fluctuations in the short ultraviolet emission from the sun $[1,2,3],{ }^{1}$ which appear to be associated with sunspots and other solar activity, no extensive study has been made either of variation of solar radiant energy at these wavelengths or of ozone changes accompanying them. It is assumed, however, and the present work seems to bear this out, that any change in the relative spectral energy within the range of 3,000 to $3,400 \mathrm{~A}$ is small or nonexistant. Hence, it is believed that changes in solar emission may be neglected without introducing a serious error in the determinaton of the total amount of ozone at any particular time.

\footnotetext{
${ }^{1}$ Figures in brackets indicate the literature references at the end of this paper.
} 


\section{Instruments and Methods}

In this work the two Westinghouse type 767 titanium phototubes (No. 1 and No. 4) and four filters, together with the sensitive d-c amplifier, were employed, as described in previous papers $[4,5]$, in connection with the determination of ultraviolet solar radiant-energy intensities. As a matter of fact, some of the solar data employed in the present determinations were included in the earlier reports. In the present case, however, attention is given only to their use in ozone determinations.

The general method employed in the reduction of the data in the present work is the same as that previously used and described in detail elsewhere $[6,7,8]$. The relative spectral response curves of the two phototubes, the spectral transmittances of the four filters, spectral transmittance curves for selected amounts of ozone, and Rayleigh scattering transmittance factors for various air masses are given in figures 1 and 2 to illustrate the general region of the spectrum involved in the measurements and calculations. For detailed information regarding the method, reference should be made to the previous publications. In general, measurements were made alternately with two phototubes

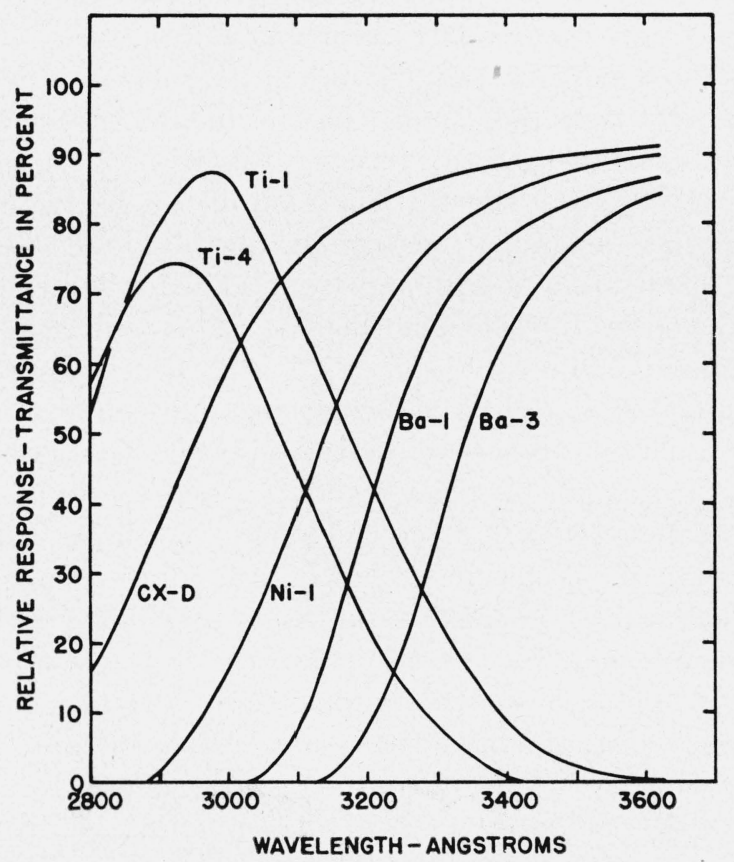

Figure 1. Relative spectral response curves for the two titanium phototubes, also the spectral transmittances of the four filters.

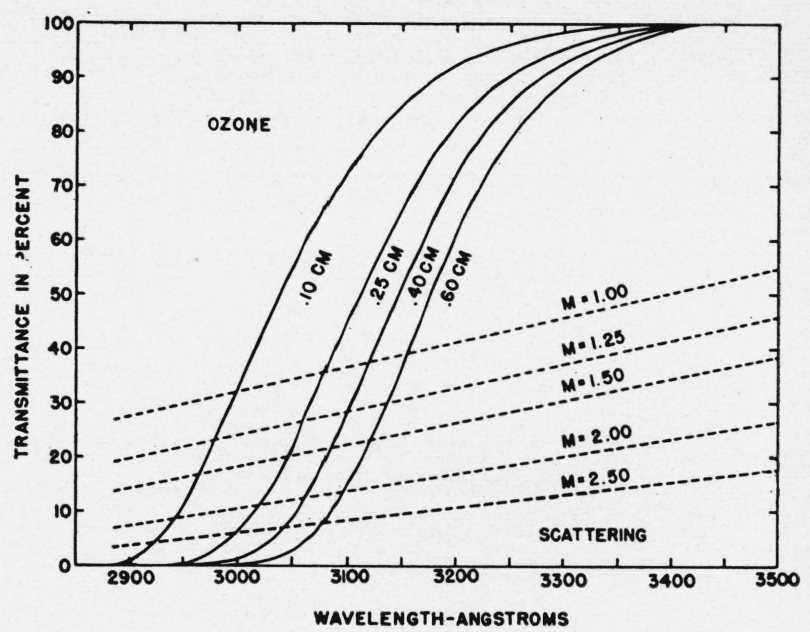

FiguRE 2. Spectral transmittance of the atmosphere in terms of molecular (Rayleigh) scattering and ozone absorption.

Scattering data are given for several air masses, $M$; ozone transmission data are given for varying thicknesses of ozone, normal-temperature pressure.

and four filters. However, on many days when only a few measurements were possible, especially during the winter months, because of changing weather conditions, only one phototube was employed. As the two phototubes and the separate filters were calibrated independently, it is to be expected that the eight determinations (using 2 phototubes and 4 filters) of ozone from any one complete set of measurements would be scattered over a limited range. Hence, to reduce this scattering to a minimum, a mean is taken for the four filter measurements and plotted (see fig. 4) in the illustration as a single ozone determination. A second adjustment, amounting to $0.01 \mathrm{~cm}$ of ozone, was made to bring the data for the two phototubes into agreement, so that on days when a single phototube was employed the values obtained would be representative of the mean for the two tubes. The data shown in figure 4 are representative of individual determinations on 4 days having high, medium, and low amounts of ozone. From each daily curve a weighted mean value was obtained for use in figures 5 to 10 , inclusive (values from 10:00 a. m. to 2:00 p. m. were given greater weight).

\section{Solar Energy Curve}

The determination of ozone by this method is based upon an energy curve of the sun outside the earth's atmosphere. Measurements have been 


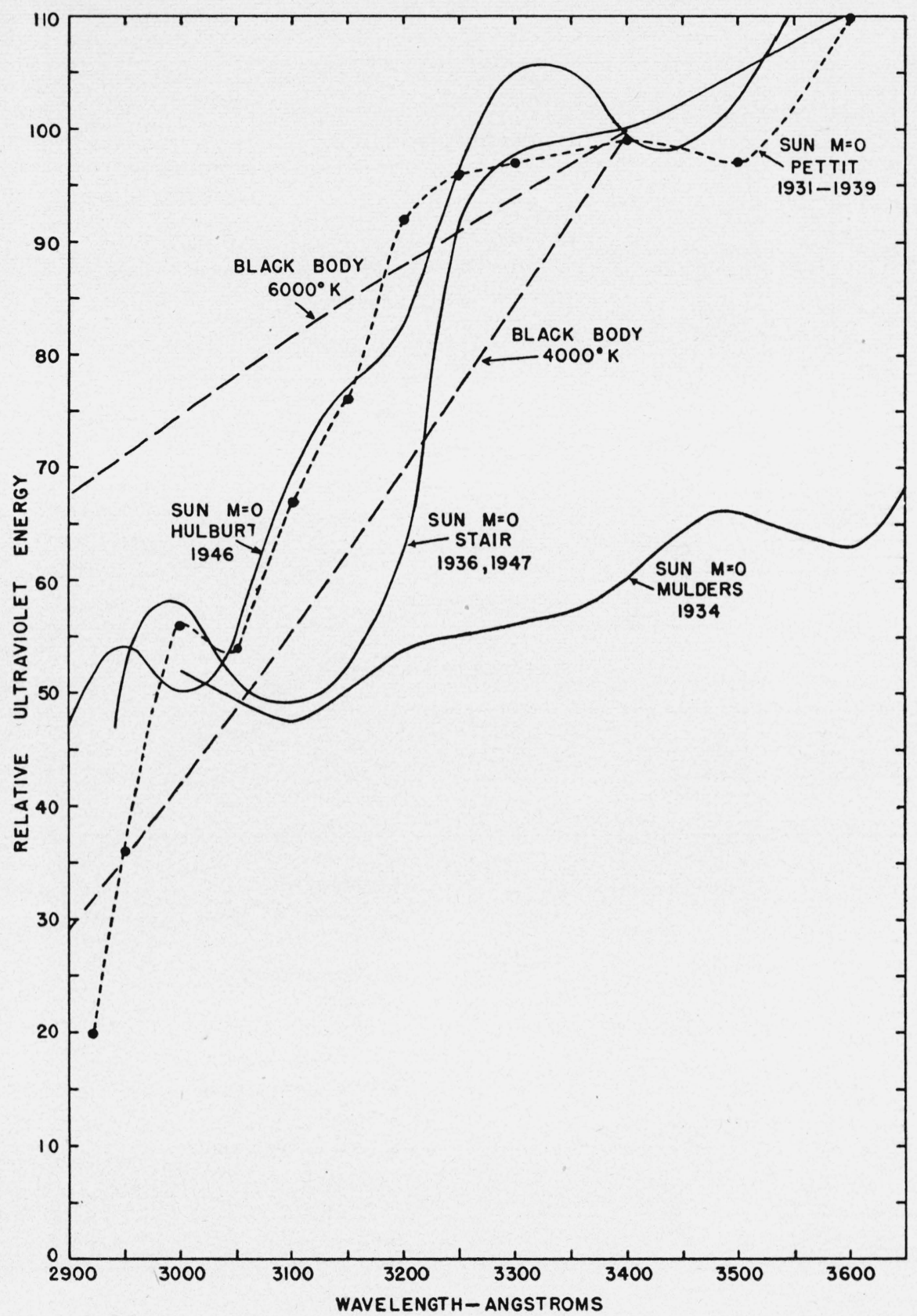

Figure 3. Distribution of energy in the extreme ultraviolet of the solar spectrum.

The ordinates for the Pettit and Stair curves are given in terms of microwatts per square centimeter per 10 angstroms. For the other solar curves and for the two black body temperatures the ordinates are arbitrary.

made by many observers, but in most cases the data either do not include the region of 3,000 to $3,400 \mathrm{~A}$, or else they are insufficiently accurate for the purpose. Some of the best data extending to even below 3,000 A were obtained at $\mathrm{Mt}$. Wilson Observatory by Pettit [9]. However, the use of wide slits (about $100 \mathrm{~A}$ ) by Pettit, together with the low sensitivity of the equipment, as well as the fact that in many of the measurements only a segment of the solar disk was employed, render the short wavelength ultraviolet data much less useful. Data published by Mulders [10] extend to $3,000 \mathrm{~A}$, but they likewise lack sufficient wavelength dispersion to show more than a rough 


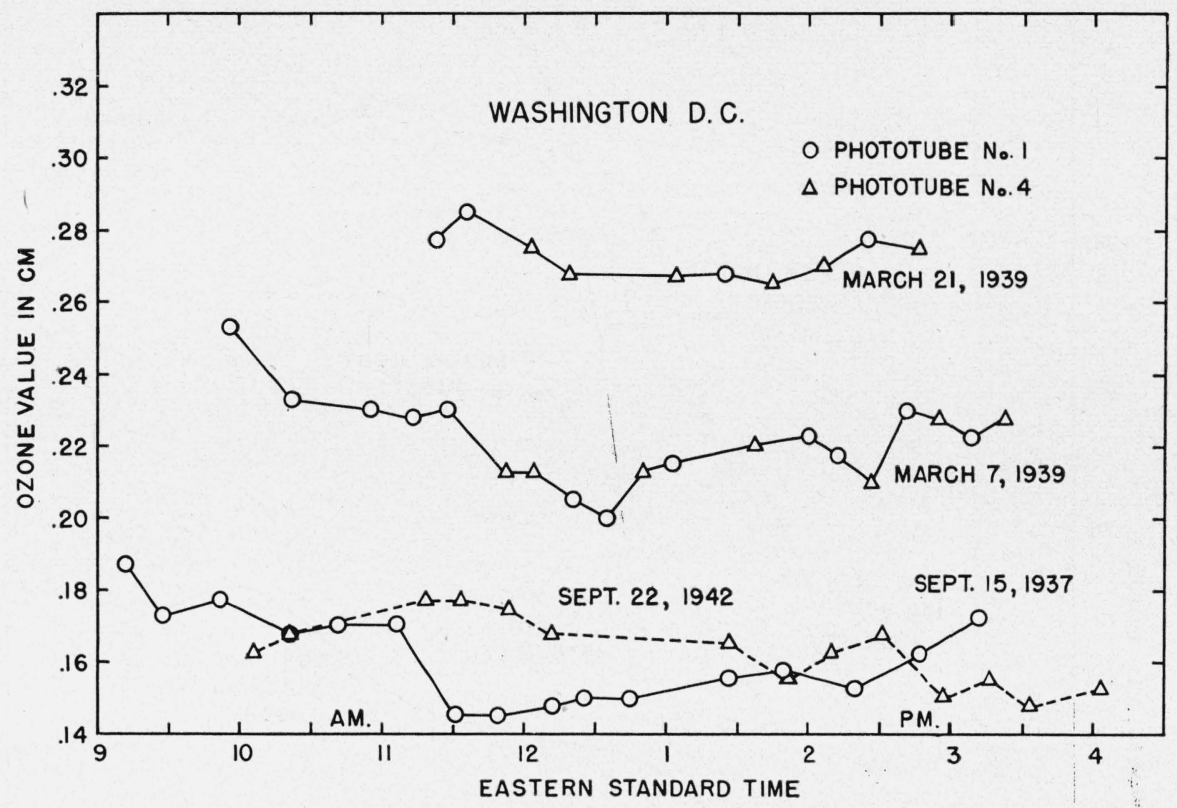

Figure 4. Individual ozone determinations with the two phototubes for days on which there were large, medium, or small amounts of ozone.

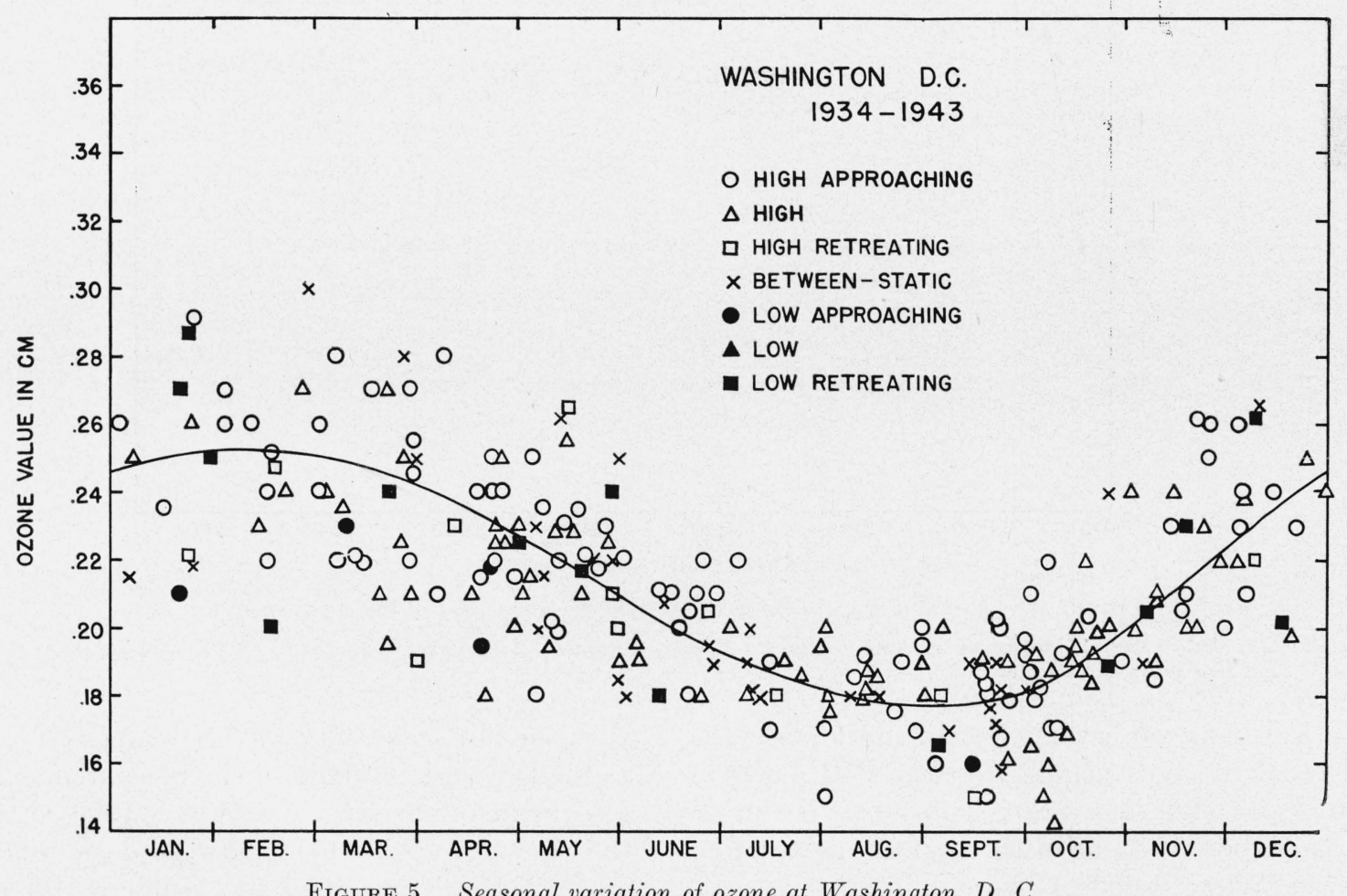

Figure 5. Seasonal variation of ozone at Washington, D. C. 


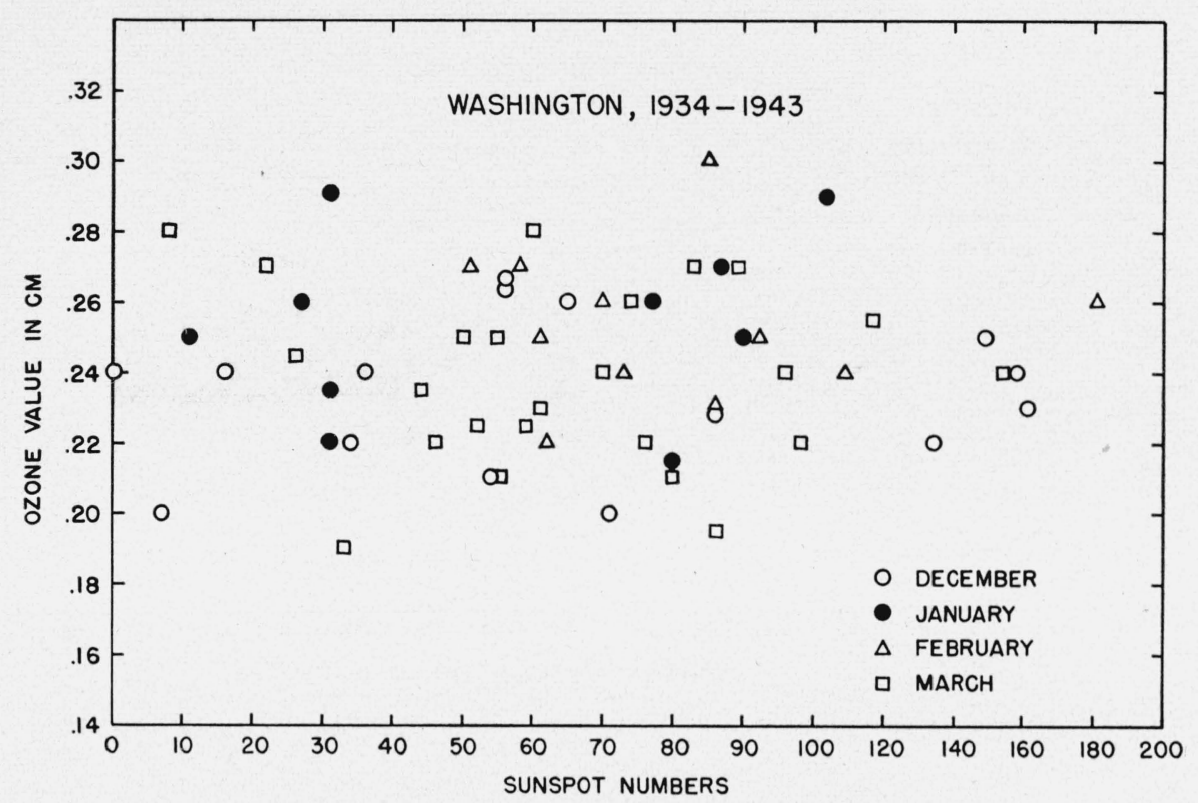

Figure 6. Plot of amount of ozone and sunspot number.

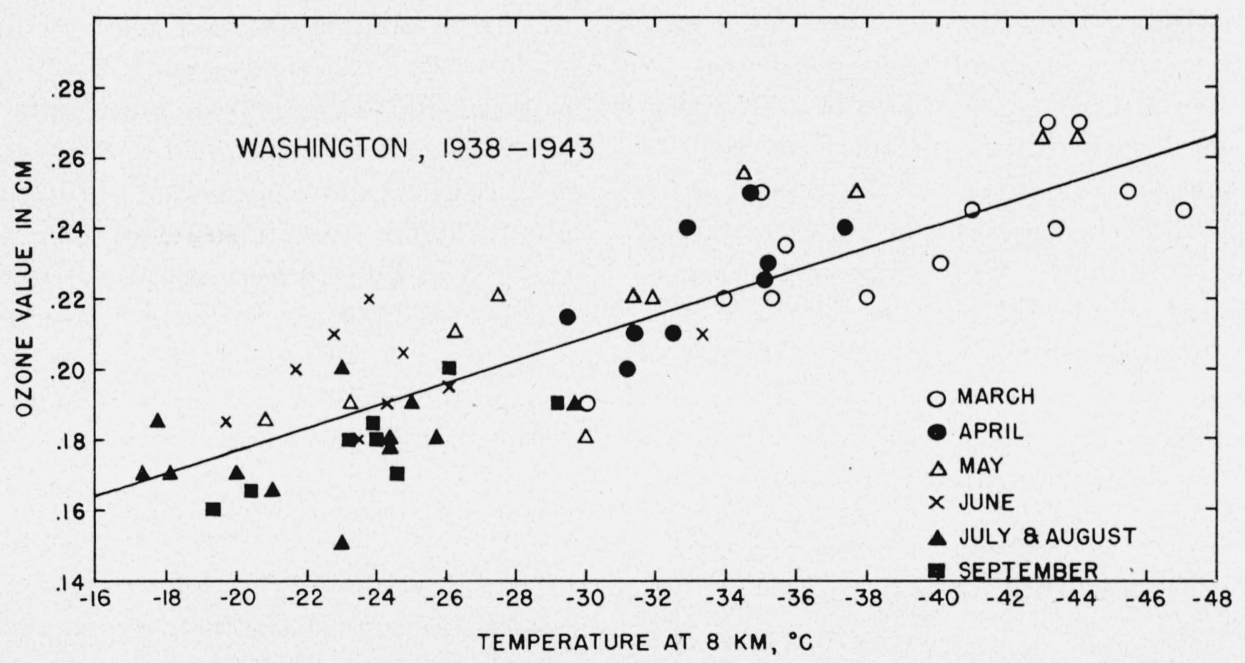

Figure 7. Positive correlation in the spring, summer, and fall between the amount of ozone and air temperatures at an altitude of $8 \mathrm{~km}$.

Fraunhofer structure. In general, measurements by Abbot [11], Götz [12], Reiner [13], Hess [14], Cabry and Buisson [15], and others give few or no iseful data within the spectral region from 3,000 to about $3,400 \mathrm{~A}$, that is, within the spectral region employed in this investigation.

Instruments transported aloft by rockets offer reat promise, as exemplified by a single prelimnary set of data recently reported by Hulburt 16]. Although obtained under adverse condiions, these data are no doubt the best available for the spectral region of 3,000 to $3,400 \mathrm{~A}$. The published curve is, however, the upper envelope of the solar intensity curve and does not include the dips due to Fraunhofer lines. When additional data of this type have been obtained and proper corrections made for Fraunhofer and other line and band absorption, the measurement of ozone concentration will have been established on a much firmer basis. Meanwhile it becomes necessary either to assume or calculate a solar energy curve applicable to the measurements 


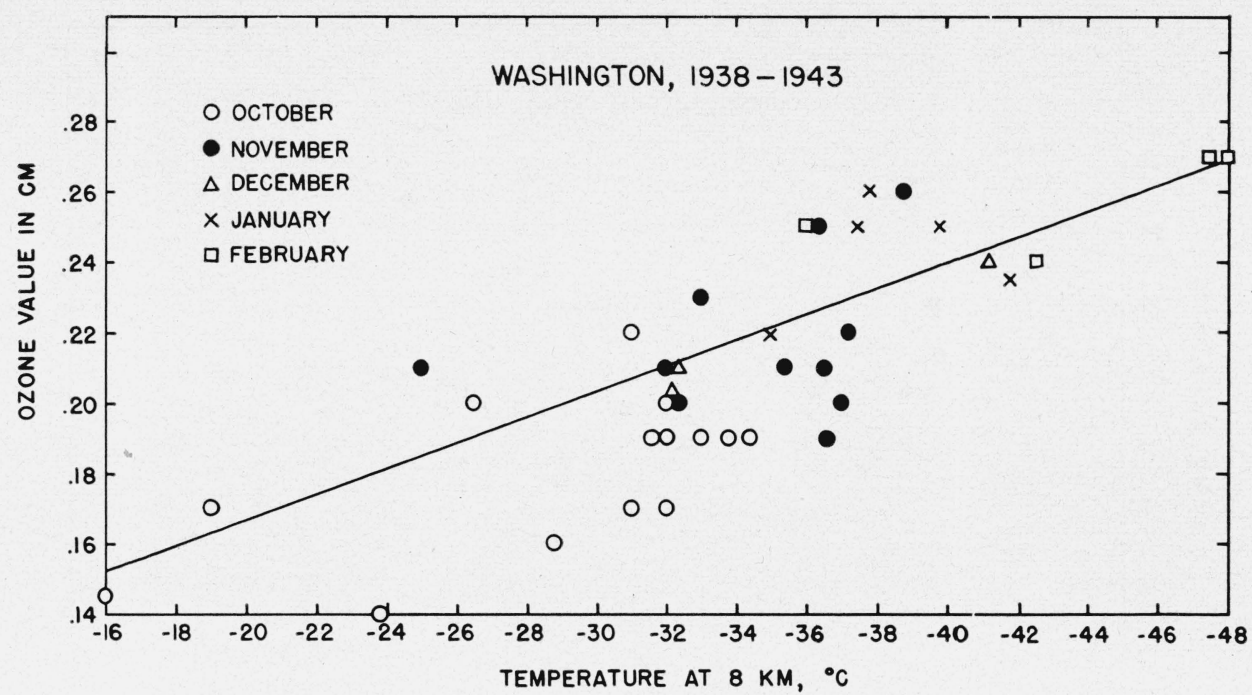

Figure 8. Positive correlation in the winter between the amount of ozone and air temperatures at an altitude of $8 \mathrm{~km}$.

being made. For the present work, the relative energy curve obtained and employed in previous work $[6,7,8]$ has been used. This calculated curve, together with some of those observed by others, is shown in figure 3 . It is to be noted that this curve was obtained by a phototube and filter integration method and may not be precise with regard to specific features, as the curve obtained is simply a smooth curve, which appears to represent best the experimental data on which it was based. On the other hand, the curves obtained by Pettit or by the Naval Research Laboratory in the rocket experiment are not fully corrected for Fraunhofer absorption lines and bands. The

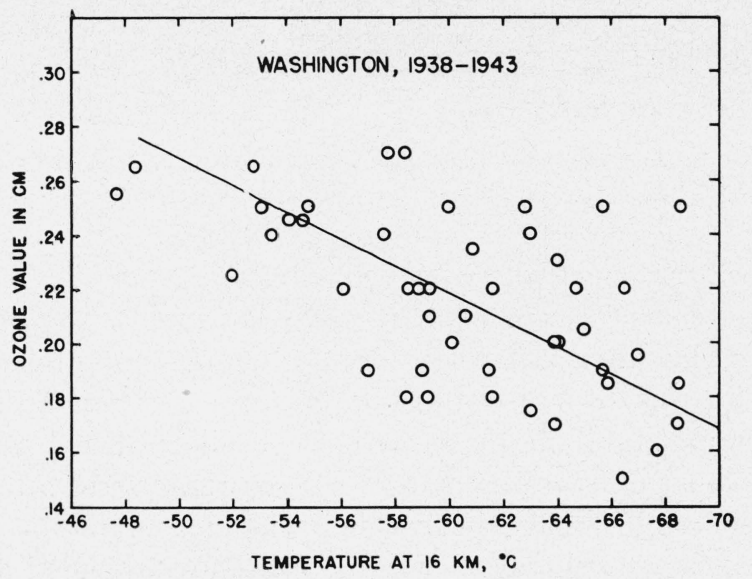

Figure 9. Negative correlation during the year between the amount of ozone and air temperatures at an altitude of $16 \mathrm{~km}$. calculated curve is preferred and used in this work because its use results in closer agreement with the experimental data for high air masses relative to low air masses, as pointed out in a previous report [8]. The broad minimum located near $3,100 \mathrm{~A}$ is not substantiated by the NRL data [16], which show a lesser minimum located at about 3,000 A. In some of Pettit's [9] data a marked minimum appears about midway between 3,000 and 3,100 $\mathbf{A}$, whereas Mulders [10] shows it located at $3,100 \mathrm{~A}$. Hence it is not possible at the present time to set up any solar energy curve between 3,000 and $3,400 \mathrm{~A}$ with certainty.

It is, of course, further recognized that the use of a fixed solar energy curve within the spectral region of 3,000 to $3,400 \mathrm{~A}$ allows no liberty for actual variations in its shape from day to day as the result of solar activity. If the short wavelength ultra. violet should increase relative to the longer wavelengths, the effect would be equivalent to an ind;cated decrease in ozone. Then if more ozone is produced by the more intense ultraviolet, the over-all effect reduces, apparently, to the case of constant ozone and constant spectral quality of solar radiant energy. This explanation is fairly well contradicted, however, by the fact that large short-time fluctuations in ozone amount are not observed, as would be expected if the spectral quality changed and ozone measurements were made before an equilibrium condition could be reached. 


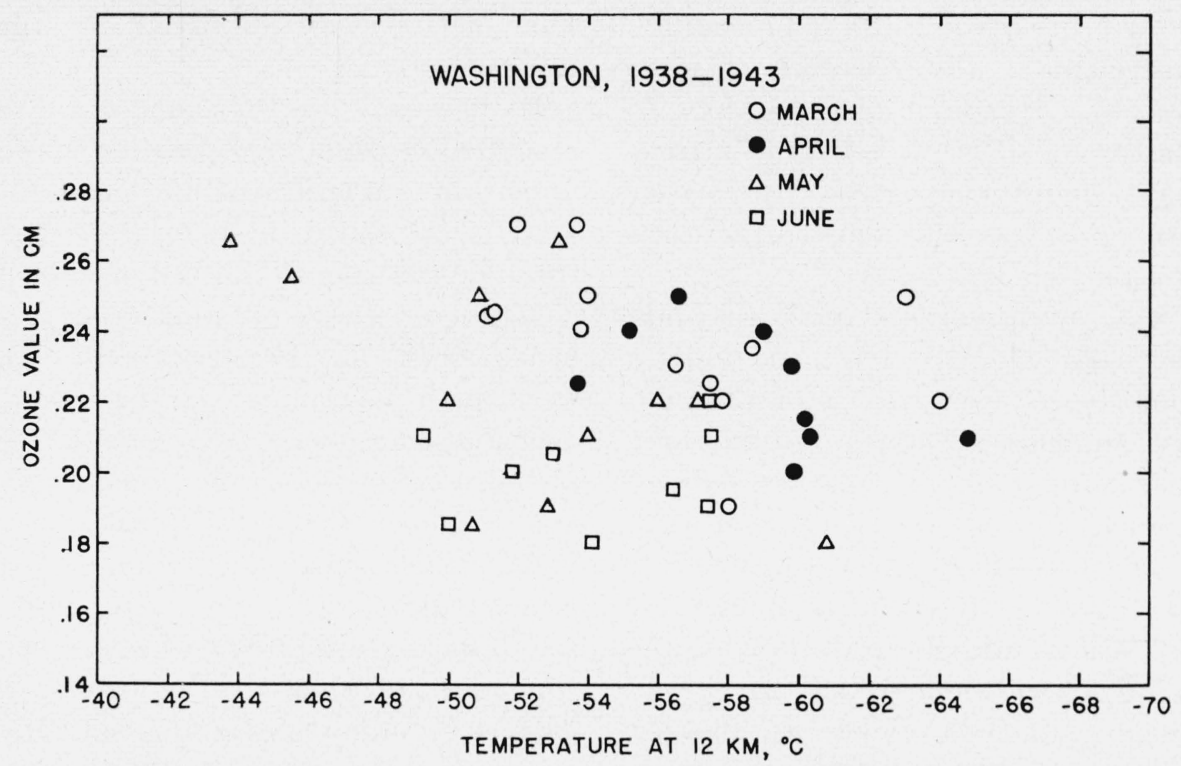

Figure 10. Low correlation in the spring and early summer between the amount of ozone and air temperatures at an altitude of $12 \mathrm{~km}$.

\section{Amount of Atmospheric Ozone}

The mean amount of ozone, based on the calculated solar energy curve of figure 3 , is displayed in figure 5 for each day on which observations were made during the 9-year period extending from May 1934 to April 1943. Each point shown on the diagram is displayed in terms of the general pressure condition existing on that particular day, so that any obvious relationship between pressure pattern and amount of ozone should be revealed. The pressure patterns were obtained from U. S. Weather Burean surface maps. The smooth curve representing the seasonal variation in ozone was simply located, without resort to mathematical calculation, in such a manner that an approximately equal number of observed points fell on each side of the line. (The same simple procedure was applied to the other illustrations.)

Several things are worthy of note in this illustration other than the fact that the observed seasonal variation agrees in both magnitude and time with that obtained by other observers $[17,18,19,20]$ for similar latitudes. Although there appears to be no observable relationship between pressure pattern and total amount of ozone, it is during those periods of the year, namely the late fall, winter, and spring, when pressure pattern changes are pronounced, that both high values and erratic changes in ozone are observed, whereas during the summer "quiescent" period the ozone value remains low and relatively constant.

Although it does not seem possible to establish any definite connection between the pressure pattern and ozone value, there is a relationship between air movements and ozone concentration. The seeming noncorrelation between cylconic areas and ozone can be accounted for by the multiple types of synoptic air masses reaching the Washington Area. For example, Dobson and his collaborators [17] found the highest ozone values above the rear of cyclones in western Europe, while Lejay [21, 22] found the highest ozone during anticyclonic weather in eastern China. This apparent discrepancy has been analyzed by Haurwitz [23] on the basis of the height of the synoptic air mass, that is, in both cases the ozone would be highest in cyclones at high levels and lowest in anticyclones at high levels. If the present data could be analyzed after this fashion, a similar relationship would probably result, judging from the temperature relationships given in a later section of this paper.

An attempt was made in figure 6 to reveal any simple relation between total ozone and solar disturbances. For this purpose, use was made of the sunspot numbers [24] recorded for the days on which observations were made. No correlation appears to exist. In a similar manner, when the ozone values were plotted as a function of the total 
sunspot number for a period of 10 days preceding the ozone measurements, the correlation was again essentially zero. Hence, it appears that if there is any change in short wavelength ultraviolet solar radiant energy associated with excess solar sunspot activity, it has little effect upon the total ozone over a particular locality.

According to the investigations of Wulf and Deming and others [20, 25, 26], excess accumulation of ozone would be reduced greatly because of two facts. First, the photochemical production of ozone occurs principally at altitudes exceeding $30 \mathrm{~km}$, below which level is 90 percent of the ozone present at any time within the atmosphere; and secondly, an equilibrium condition in the amount of ozone above the level of maximum concentration is quickly restored once it has been disturbed. According to their views, we should probably not expect to find a definite correlation between amount of ozone and the magnitude of

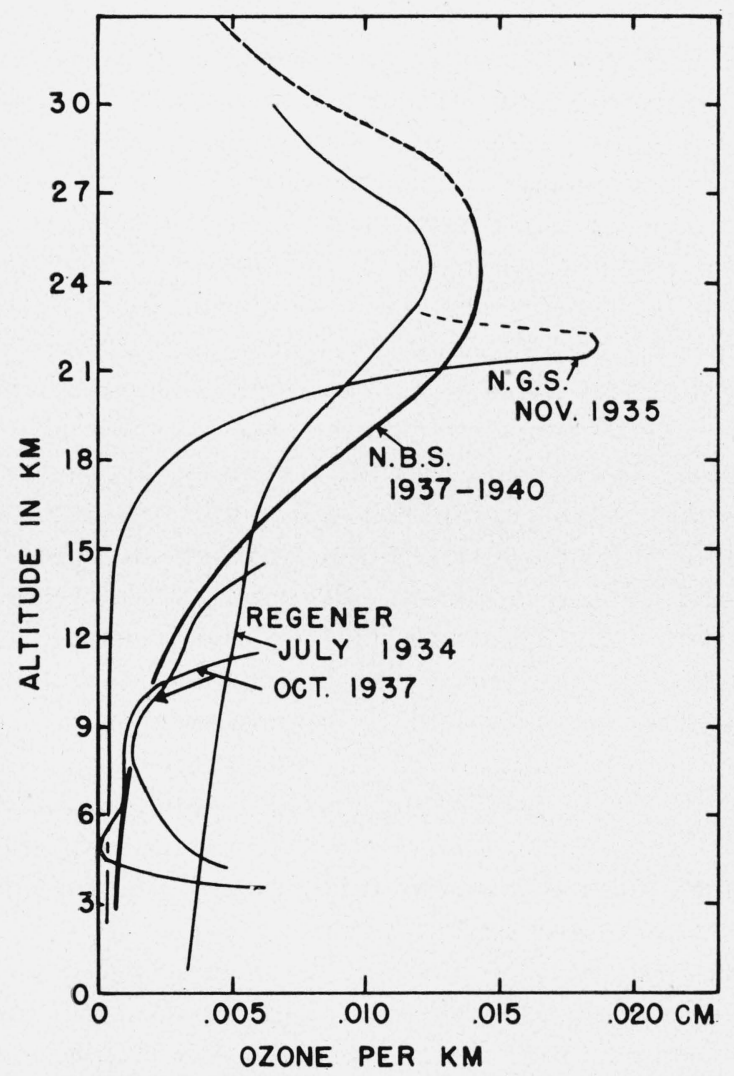

FIgURE 11.-Vertical distribution of ozone in the stratosphere.

The NBS curve is the mean of June and early July measurements obtained in 18 unmanmed balloon flights during the four years, 1937 to 1940. solar activity as indicated by the number of sunspots [42].

In figures 7 to 10 some of the data on total amount of ozone are plotted as a function of upper-air temperatures measured at Washington, D. C., by the United States Weather Bureau through the use of the radiosonde [27]; the temperature data were obtained from Weather Bureau files. Most of the temperature measurements were made near noon on the days on which the ozone measurements were made. In some cases the data were taken in the early morning hours, and in some others it was necessary to use midnight values because of failure of midday radiosonde flights. For the greater part of the work, the upper air temperatures correspond in both time and place with the ozone measurements. This is an important factor, since radical changes in upper-air conditions often occur within $12 \mathrm{hr}$.

In the work of Meetham [28, 29], many of the radiosonde measurements were made at points 50 to 120 miles distant, so that entirely different upper-air conditions could easily have prevailed between the two stations. Nevertheless, his work shows a certain amount of correlation between ozone and upper-air temperatures, pressures, height of tropopause, etc., but not of the magnitude existing in the present work and most beautifully displayed (in fig. 7) by the springsummer-fall values for an altitude of $8 \mathrm{~km}$. The winter values for the same altitude shown in figure 8 scatter more for a number of reasons, such as instrumental errors as a result of low solar intensity, small uncorrected temperature coefficients of the glass filters, and greater dust and smoke scattering, which, spectrally, may not be entirely nonselective.

If the ozone values are plotted as a function of the upper-air temperature at some point well within the stratosphere, for example at $16 \mathrm{~km}$ (see fig. 9), there is a much lower correlation between the two, and it is opposite to that existing in the region of $8 \mathrm{~km}$. At $12 \mathrm{~km}$, just above the tropopause (see fig. 10), the correlation is still lower-in fact it is near zero, as is to be expected, at or near the tropopause. Inasmuch as the mean altitude of the tropopause shifts with the season of the year, one might expect a seasonal shift in the ozone-temperature correlation curves.

If the correlation had been made in terms of the amount of ozone as a function of the altitude of 


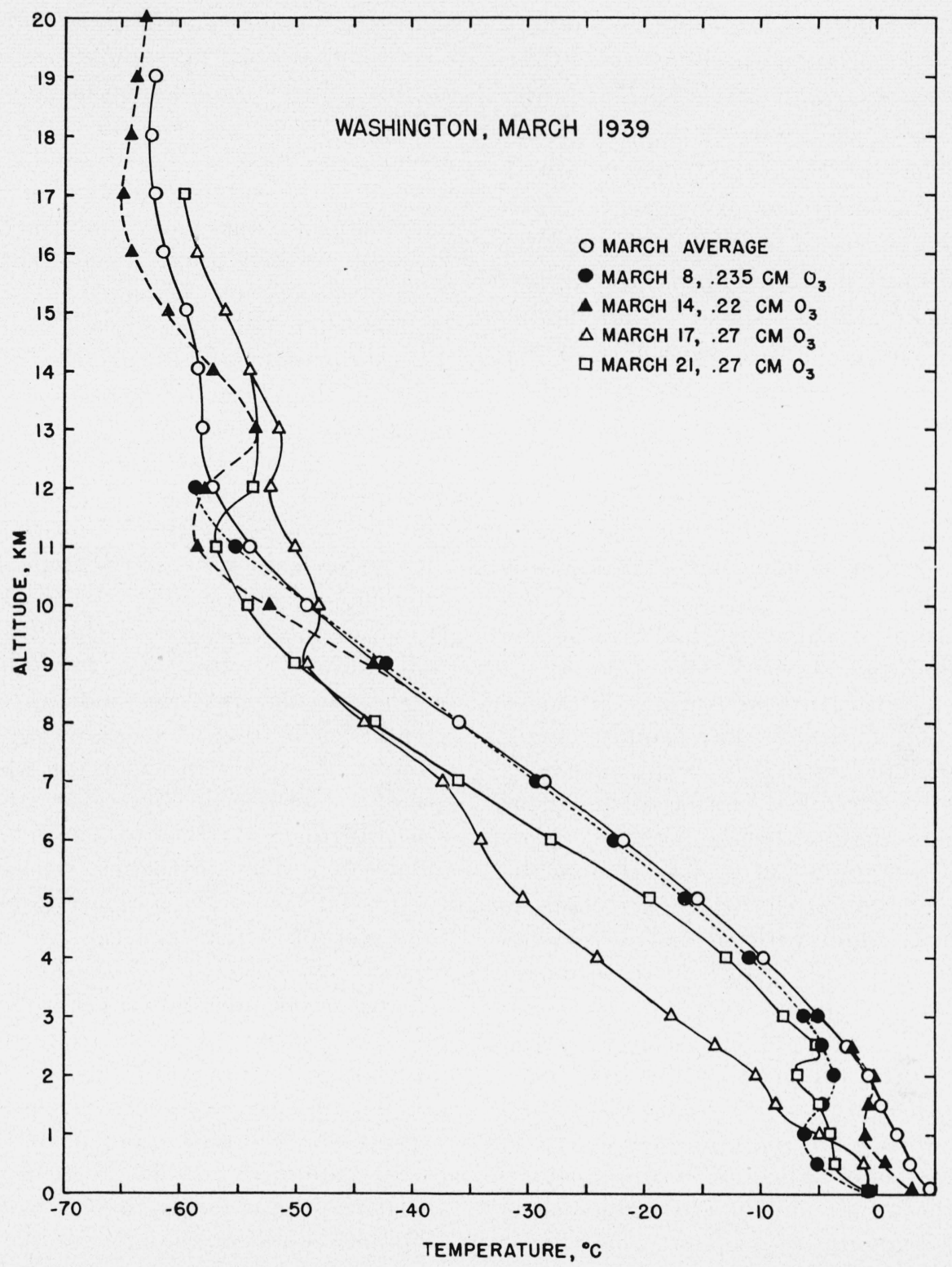

Figure 12. Some March 1939 air temperatures as a function of the altitude on days of high and of low amounts of ozone. These data were obtained by the U.S. Weather Bureau through the use of the radiosonde.

the tropopause, the agreement would probably be as good as in the case when correlated with the temperature at $8 \mathrm{~km}$, since the tropopause shifts with temperature changes below that level. In other words, high ozone values are associated with low tropopause altitudes as previously found by Meetham [29].

\section{Discussion of the Ozone Data}

The ozone data recorded herein show, in agreement with other investigations $[17,18,19,20,30$,
31, 39], in particular that of Dobson and Götz, a marked seasonal variation. They also show significant changes that are in some way connected with air mass movements, but which cannot be tied down to surface conditions of pressure, temperature, etc. The curves reproduced in figures 11 and 12 , relative to the vertical distribution of ozone [33 to 40], and those for measured air temperatures as a function of altitude for several days on which measurements were made indicate a very close relationship between the position of 
the ozone band and normal atmospheric characteristics. Very little ozone normally exists within the troposphere as the result of air currents that rapidly bring it into conditions of pressure, temperature, etc., that accelerate its degeneration. This fact is illustrated by the experimental data reproduced in the curves of figure 11, which show but little ozone until altitudes above the tropopause are reached. Hence, the irregularities in the temperature curves in the lower part of the atmosphere (see fig. 12) would not be expected to affect directly the amount of ozone in any way. It is only when something happens at a much higher level, in general, to change effectively the position of the tropopause, that fluctuations in the ozone value would be expected. An analysis of the curves of figure 12, taking into account the vertical distribution of ozone (see fig. 11) and the observed relationship between the amount of ozone and the temperature at various altitudes (see figs. 7 to 10), indicates that ozone changes are directly associated with air movements above about 6 or $8 \mathrm{~km}$. A vertical motion of the air at these levels would change the temperature below and above the tropopause, as well as change the tropopause level. Similar changes in atmospheric characterics would result with lateral movements of air from other latitudes. Both of these movements occur, as can be determined by cloud movements. As a matter of fact, rapid vertical motions at altitudes as high as $25 \mathrm{~km}$ have been observed by Stormer [41]. Both high-vertical and lateral-air movements are sometimes observed in trails left by meteors. The relative importance of these two types of air movements in increasing or decreasing the amount of ozone at a particular station is unknown.

A combination of air motions wherein a significant part of the ozone layer moves downward, together with a lateral inward motion of air of high ozone content, could be expected to result in a very high ozone value. Similarly, an opposite type of air motion should produce a very low ozone value. In either case, any disturbance within the upper 10 percent of the ozone layer would rapidly be brought to equilibrium as the result of normal photochemical reactions.

If the measurement of ozone should be placed on a routine basis and correlated with other upper- air measurements at a number of stations within a continental area, for example, much information on this subject should soon become available.

The existence of a noon "dip" in the daily ozone curve (see fig. 4) continuing into the afternoon may be subject to some question, as it is not found in any early published investigation available to the author. A noon dip has, however, been observed and described in recent papers by Ramanathan [43] and by Karandikar [44]. The noon dip is not large but nearly always occurs not only in the data for Washington, but also in measurements made in both mountain and desert $[5,6,7,8]$ locations using the same or similar instruments. If the noon dip is real, its magnitude may be even larger than indicated in figure 4, as its existence is very much dependent upon the solar energy curve employed in the calculations. If one of the curves as observed by Pettit [9], or that obtained by the NRL [16] group, be employed in the calculations, the noon dip is appreciably greater. The total ozone value is also greater. To remove effectively the noon dip would require the use of a solar energy curve even steeper within the spectral range of 3,100 to $3,400 \mathrm{~A}$ than that now employed. This procedure seems unjustified at the present time. It is rather to be expected that the noon dip is real, and that we should credit its existence to either a diurnal decrease in ozone or to some other variable atmospheric condition that affects the relative spectral transmittance of the atmosphere. Changes in size of water particles or amount of dust have been suggested, but neither existed in appreciable quantity in the case of some of the mountain and desert measurements. Furthermore, there seems to be no obvious relationship between local humidity and observable dustiness and apparent ozone value from measurements made on days when they are high. Recent extensive measurements made by the author at a high altitude station in southern New Mexico, where haze and humidity are extremely low, should, when reduced, do much toward clearing up the question of a noon dip in ozone value.

In conclusion, a question may be raised about possible errors in all past ozone work resulting from unknown or uncorrected temperature coefficients [45]. The high correlation between zonal air temperatures and ozone amount observed in this work may be significant in this respect. 


\section{References}

[1] C. G. Abbot, Solar variation and forecasting, Smithsonian Misc. Collections 7\%, No. 5 (1925).

[2] Edison Pettit and S. B. Nicholson, Radiation measurements on the corona, Pubs. Astron. Soc. Pacific 37, 152 (1925).

[3] G. M. B. Dobson, Measurements of the sun's ultraviolet radiation and its absorption in the earth's atmosphere, Proc. Roy. Soc. London [A], 104, 252 (1923).

[4] W. W. Coblentz and R. Stair, Factors affecting ultraviolet solar-radiation intensities, J. Research NBS 15, 123 (1935) RP816.

[5] W. W. Coblentz and R. Stair, Evaluation of ultraviolet solar radiation of short wave lengths, J. Research NBS 16, 315 (1936) RP877.

[6] R. Stair and I. F. Hand, Methods and Results of Ozone Measurements over Mount Evans, Colo., Monthly Weather Rev. 67, 331 (1939).

[7] Ralph Stair, Measurements of Ozone over the Organ Mountains, New Mexico, J. Research NBS 40, 9 (1948) RP1851.

[8] Ralph Stair, Winter Measurements of Ozone over the Organ Mountains, New Mexico, J. Research NBS 42, 145 (1949) RP1958.

[9] Edison Pettit, Spectral Energy-curve of the Sun in the Ultraviolet, Astrophys. J. 91, 159 (1940).

[10] G. F. W. Mulders, Aequivalente Breedten Van Fraunhoferlijnen in Het Zonnespektrum, Dissertation, Nijmegen (1934).

[11] C. G. Abbot, F. E. Fowle, and L. B. Aldrich, The Distribution of Energy in the Spectra of the Sun and Stars, Smithsonian Misc. Collections 74, No. 7 (1923).

[12] F. W. Paul Götz and Ernst Schönmann, Die spectrale Energieverteilung von Himmels- und Sonnenstrahlung, Helv. Phys. Acta 21, 151 (1948).

[13] Heinz Reiner, Die Struktur des Sonnen Spektrums Zwischen 400 und $600 \mathrm{~m} \mu$, Gerlands Beitr. Geophys., 55, Heft 2, 234 (1939).

[14] Paul Hess, Untersuchungen über die spektrale Energie-verteilung im Sonnenspektrum von 350 $\mathrm{m} \mu$ bis $500 \mathrm{~m} \mu$, Inaugural-Dissertation, Universität Frankfurt a. M. (1938).

[15] C. Fabry and M. Buisson, Etude de l'éxtremité ultraviolete du Spectre solaire, J. phys. radium $\boldsymbol{2}, 197$ (1921).

[16] E. O. Hulburt, The Upper Atmosphere of the Earth, J. Opt. Soc. Am. 37, 405 (1947).

[17] G. M. B. Dobson, D. N. Harrison, and J. Lawrence, Proc. Roy. Soc. London [A] 114, 521 (1927); [A] 122, 456, (1928).

[18] F. W. P. Götz, Ergeb. Kosmichen Phys. III, 253 (1938).

[19] F. W. P. Götz, Der Stand des Ozonproblems, Vierteljahrsschr. naturforsch. Ges. Zürich 89, 250 (1944).
[20] Richard Ansel Craig, The observations and photochemistry of atmospheric ozone and their meteorological significance. (Thesis, Mass. Inst. of Tech., 1948).

[21] Rev. Pierre Lejay, Quart. J. Roy. Meteorol. Soc., Atm. Ozone, Suppl. to Vol. 62 (1936).

[22] Rev. Pierre Lejay, Ozone Measurements and Currents in the Stratosphere, Bul. Am. Meteorol. Soc. 20, 298 (1939.)

[23] B. Haurwitz, Atmospheric Ozone as a Constituent of the Atmosphere, Bul. Am. Meteorol. Soc. 19, 417 (1938).

[24] W. Brunner, Sunspot Numbers for 1934-1943, Terr. Mag. and Atmos. Elec. 40 to 49 (1935-44).

[25] O. R. Wulf and L. S. Deming, Terr. Mag. and Atmos. Elec. 41, 299, 375 (1936); 42, 195 (1937).

[26] Oliver Reynolds Wulf, Proc. Eighth Am. Sci. Congr. VII, 439 (1940).

[27] H. Diamond, W. S. Hinman, and F. W. Dunmore, The Development of a Radio Meteoragraph System for the Navy Department, Bul. Am. Meteorol. Soc. 18, 95 (1937).

[28] A. R. Meetham, Correlation of Atmospheric Ozone with other Geophysical Phenomena, Quart. J. Roy. Meteorol. Soc. Suppl. to vol. 62, p. 59 (1936).

[29] A. R. Meetham, The Correlation of the Amount of Ozone with other Characteristics of the Atmosphere, Quart. J. Roy. Meterolog. Soc. 63, 289 (1937).

[30] G. M. B. Dobson and A. R. Meetham, Quart. J. Roy. Meteorol. Soc. (London) 60, 265 (1934).

[31] G. M. B. Dobson, Proc. Roy. Soc. London [A] 129, 411 (1930).

[32] G. M. B. Dobson, A. W. Brewer, and B. M. Cwilong, Proc. Roy. Soc. London [A] 185, 144 (1946).

[33] R. Stair and W. W. Coblentz, Radiometric Measurements of Ultraviolet Solar Intensities in the Stratosphere, J. Research NBS 20, 185 (1938) RP1075.

[34] W. W. Coblentz and R. Stair, Distribution of Ozone in the Stratosphere, J. Research NBS 22, 573 (1939) RP1207.

[35] W. W. Coblentz and R. Stair, Distribution of Ozone in the Stratosphere: Measurements of 1939 and 1940, J. Research NBS 26, 161 (1941) RP1367.

[36] E. Regner and V. H. Regner, Aufnahmen des ultravioletten Sonnenspektrums in der Stratosphäre und die vertikale Ozonverteilung, Phys. Z. 35, 788 (1934).

[37] Brian O'Brien, H. S. Stewart, and F. L. Mohler, Vertical Distribution of Ozone in the Atmosphere, Nat. Geogr. Soc. Contrib. Tech. Papers, Stratosphere Series No. 2, page 49, 1936.

[38] V. H. Regner, Neue Messungen der vertikalen Verteilung des Ozons in der Atmosphäre, Phys. Z. 109, 642 (1938).

[39] E. Tonsberg and K. L. Olsen, Investigations on Atmospheric Ozone at Nordlysobservatoriet, Tromso, Geof. Pub. 13, No. 12 (1944). 
[40] A. R. Meetham and G. M. B. Dobson, The Vertical Distribution of Atmospheric Ozone in High Latitudes, Proc. Roy. Soc. London 148, 598 (1935).

[41] C. Stormer, Höhe und Farbenverteilung der Perlmutterwolken, Geophys. Pub. IX, No. 4 (1932).

[42] B. Haurwitz, Relations Between Solar Activity and the Lower Atmosphere, Trans. Am. Geophys. Union, 2\%, 161 (1946).
[43] K. R. Ramanathan, Assemblée UGGI, Oslo (1946).

[44] R. V. Karandikar, Studies in Atmospheric Ozone, Proc. Indian Acad. Sci. 28, 63 (1948).

[45] Vassy and Vassy, Variation diurne de la température moyenne de l'ozone atmosphérique, Compt. rend. 228, 764 (1949).

Washington, June 8, 1949. 